\title{
Expression of 15-Hydroxyprostaglandin Dehydrogenase in Human Chorion Is Associated with Peroxisome Proliferator-Activated Receptor Isoform Expression in Term Labor
}

\author{
Ping $\mathrm{He}^{*}{ }^{*}$ Yuan $\mathrm{Li}_{1}^{\dagger}$ Xiaoying Ding, ${ }^{\ddagger}$ Qianqian Sun, ${ }^{\dagger}$ Ying Huang, ${ }^{\ddagger} \mathrm{Hang} \mathrm{Gu},{ }^{\dagger}$ and $\mathrm{Xin} \mathrm{Ni}^{*}$
}

From the Department of Physiology, * Second Military Medical University, Shanghai; the Department of Gynecology and Obstetrics, ${ }^{\dagger}$ Changhai Hospital, Shanghai; and the Maternity and Child Health Hospital of Pudong New District, ${ }^{\ddagger}$ Shanghai, China

\author{
Accepted for publication \\ March 12, 2015. \\ Address correspondence to \\ Xin Ni, M.D., Ph.D., Depart- \\ ment of Physiology, Second \\ Military Medical University, \\ 800 Xiangyin Rd., Shanghai \\ 200433, China. E-mail: \\ nixinsmmu@hotmail.com.
}

\begin{abstract}
Chorionic NAD-dependent 15-hydroxy prostaglandin dehydrogenase (PGDH) plays a pivotal role in controlling the amount of prostaglandins in the uterus. Peroxisome proliferator-activated receptors (PPARs) are implicated to be involved in parturition. In this study, we investigated whether PPARs are involved in control of PGDH expression in chorion. The chorionic tissues were collected from the following groups of the women with singleton pregnancy: term no labor (TNL), term labor (TL) and preterm labor (PTL). Chorionic trophoblasts were isolated and cultured in vitro. Immunocytochemistry analysis showed that PPAR $\alpha$, PPAR $\beta$, and PPAR $\gamma$ were localized to trophoblasts in chorion. The protein levels of PGDH, PPAR $\beta$, and PPAR $\gamma$ were localized to trophoblasts in chorion. The protein levels of PPAR $\alpha$, PPAR $\beta$, and PPAR $\gamma$ were reduced in TL tissues compared to that of TNL group. PPAR $\alpha$, PPAR $\beta$, and PPAR $\gamma$ expression correlated to PGDH in TNL tissues, whereas only PPAR $\gamma$ expression correlated to PGDH in TL chorion tissues. PGDH expression was decreased in PTL tissues compared with TL group, whereas the expression of PPARs was not significantly different between TL and PTL groups. The agonists of three PPARs dose-dependently stimulated PGDH activity, mRNA, and protein expression in cultured chorionic cells. PPARs did not affect the stability of PGDH mRNA but stimulated the transcriptional activity of HPGD gene. Our results suggest that PPARs play pivotal roles in maintenance of PGDH expression in chorion during human pregnancy. (Am J Pathol 2015, 185: 1981-1990; http:// dx.doi.org/10.1016/j.ajpath.2015.03.021)
\end{abstract}

Mechanisms underlying the initiation of labor in humans are the subject of intense investigation. Most models of parturition incorporate prostaglandins (PGs) as signaling molecules for uterine contractions and cervical ripening. ${ }^{1-4}$ During pregnancy PGs are synthesized and secreted by gestational tissues, including placenta, fetal membranes, and myometrium. Among them, fetal membranes are the main source of PGs for the parturition within the uterus. ${ }^{5}$

PGs are formed from arachadonic acid released from membrane stores, by the action of PG $\mathrm{H}$ synthase. ${ }^{6}$ The first enzymatic step of PG metabolism is oxidation of the 15-hydroxyl group by the $\beta$-NAD ${ }^{+}$-dependent 15 -hydroxyprostaglandin dehydrogenase (PGDH) to form biologically inactive 15-keto metabolites. ${ }^{7,8}$ This reaction inactivates PGs and constitutes the key step in PG metabolism. In fetal membranes, PG $\mathrm{H}$ synthase- 2 is expressed abundantly in both amnion and chorion, whereas the main site of PGDH expression is the trophoblast layer of the chorion. ${ }^{9}$ Given that the chorion laeve is located between the amnion and the decidua, high PGDH activity in chorion constitutes a metabolic barrier which controls the concentration of active PGs that reaches to the myometrium.

A number of studies have reported that the expression and activity of PGDH in chorion are substantially down-regulated

Supported by Major State Basic Research Program of China grant 2013CB967404 (X.N.) and Natural Science Foundation of China grants 31371175 (P.H.) and 31071314 (X.N.).

P.H. and Y.L. contributed equally to this work.

Disclosures: None declared. 
with term labor (TL). ${ }^{10-16}$ In infection-associated preterm labor (PTL), a further decrease in enzyme activity and protein expression of PGDH was reported. ${ }^{12,14}$ The expression of PGDH is modulated by various factors such as steroid hormones and proinflammatory cytokines. ${ }^{15,17,18}$ However, how the PGDH in chorion is regulated during pregnancy remains largely unknown.

Peroxisome proliferator-activated receptors (PPARs) are members of the nuclear hormone receptor superfamily. Three PPAR subtypes, PPAR $\alpha$, PPAR $\beta$ (also known as PPAR $\delta$ ), and PPAR $\gamma$, which are encoded by separate genes, were identified in human placenta and fetal membranes. ${ }^{19-22}$ PPARs are involved in several aspects of pregnancy development, including implantation, placentation, and trophoblast differentiation. ${ }^{23-25}$ A number of studies have shown that the expression of PPARs changes with labor at term and preterm in the placenta and fetal membrane but with inconsistent results. Holdsworth-Carson et $\mathrm{al}^{26}$ have shown that the protein expression of three PPARs substantially increases during labor in placenta but not in fetal membranes during labor at term. A study by the same group found that the expression of PPAR $\beta$ and PPAR $\gamma$ in the placenta and PPAR $\beta$ in fetal membranes increases in labor at preterm. ${ }^{27} \mathrm{In}$ contrast, Berry et $\mathrm{al}^{21}$ reported that PPAR $\alpha$ mRNA in choriodecidua declines with labor, whereas PPAR $\gamma$ and PPAR $\beta$ mRNA remain unchanged with labor.

Like other nuclear hormone receptors, PPARs act as ligand-dependent transcription factors in many cellular pathways. Receptor ligation results in nuclear translocation, and they heterodimerize with retinoid X receptors (RXRs). These obligate heterodimers in turn bind to peroxisome proliferator-responsive elements located in the regulatory region of target genes, resulting in changes in gene transcription activity. ${ }^{28}$ Interestingly, there is a half-site of peroxisome proliferator-responsive elements in the promoter region of PGDH. Thus, whether PGDH expression is under control of PPARs in chorion becomes of interest.

We investigated the expression levels of PPARs in chorion during labor at term and at preterm, analyzed the correlation between PPARs and PGDH in chorion in labor at term and preterm, and studied the effects of PPARs on PGDH expression and the possible mechanisms by using cultured chorionic trophoblasts.

\section{Materials and Methods}

\section{Tissue Collection}

Tissue collections were performed with approval of the specialty committee on ethics of biomedicine research, Second Military Medical University, Shanghai, China. Written informed consent was obtained from all patients. Human fetal membranes were collected from the following groups of women with singleton pregnancy: term no labor (TNL; $n=24)$, term labor (TL; $n=24$ ), and preterm labor (PTL; $n=24)$. TNL tissues were collected at abdominal delivery. Indications for abdominal delivery included breech presentation, placenta previa, previous abdominal delivery, cephalopelvic disproportion, fetal distress, or maternal request. Among the TNL group, $10 \mathrm{TNL}$ tissues were used for chorionic trophoblast culture. The fetal membranes of TL were collected from women with uncomplicated pregnancies, who went into natural labor, and delivered vaginally. The patients exhibited no clinical signs of infection. The preterm fetal membranes and placentas were assessed for histopathologic evidence of infection. Of the preterm fetal membranes collected $(n=24), 8$ had confirmed chorioamnionitis (CAM), and the remaining 16 were classified with normal pathology (no evidence of infection or pathologic microflora). The patients who had the evidence of underlying disease (eg, hypertension, diabetes, preeclampsia, intrauterine growth restriction, etc.) were not included in this study.

The chorion laeve was separated, and the uniform removal of decidual tissue was monitored by using an inverted phase contrast microscope. Chorion tissues were snap-frozen in liquid nitrogen and stored at $-80^{\circ} \mathrm{C}$.

\section{Immunohistochemistry}

Paraffin sections $(5 \mu \mathrm{m})$ of fetal membrane were cut, rehydrated, and microwaved in citric acid buffer to retrieve antigens. After inhibition of endogenous peroxidases with $3 \%$ $\mathrm{H}_{2} \mathrm{O}_{2}$, unspecific antibody binding was blocked with $10 \%$ rabbit serum. The sections were then incubated with specific antibodies against human PPAR $\alpha$ (sc-9000; Santa Cruz Biotechnology, Santa Cruz, CA), PPAR $\beta$ (sc-7197; Santa Cruz Biotechnology), and PPAR $\gamma$ (sc-7273; Santa Cruz Biotechnology) at 1:200 dilution overnight at $4^{\circ} \mathrm{C}$. The bound antibodies were detected with the biotin-streptavidin-peroxidase system (UltraSensitive-SP-kit; MaiXin Biotechnology, Fuzhou, China) by using diaminobenzidine (Sigma-Aldrich, St. Louis, MO) as chromogen. Counterstaining was performed with hematoxylin. Negative controls were performed by substituting primary antibody with IgG.

\section{Chorionic Trophoblast Culture}

Chorionic trophoblasts were isolated and cultured according to the modified Kliman's method. ${ }^{29-31}$ Briefly, approximately $40 \mathrm{~g}$ of fresh chorion obtained from without labor at term patients was minced and then was dispersed with $0.125 \%$ trypsin (Invitrogen Corp., Carlsbad, CA) and $0.02 \%$ collagenase (Invitrogen Corp.) in Dulbecco's modified Eagle's medium (Sigma Chemical Co., St. Louis, MO) that contained $0.1 \%$ bovine serum albumin for three times. A purified fraction of cytotrophoblasts was obtained after Percoll (Pharmacia, Uppsala, Sweden) gradient centrifugation. Cells were then distributed into 12-well plates at a density of $1 \times 10^{6}$ per well and grown in Phenol red-free Dulbecco's modified Eagle's medium that contained $10 \%$ fetal calf serum at $37^{\circ} \mathrm{C}$ in $5 \%$ $\mathrm{CO}_{2}-95 \%$ air. Cell purity was assessed by immunostaining for cytokerain and vimentin by using primary antibodies (Dako, Inc., Carpinteria, CA) as described previously. ${ }^{30,31}$ 
After 72 hours of incubation, cells were then treated with various concentrations of the agonists of PPARs GW7647 (PPAR $\alpha$ agonist; Sigma-Aldrich), GW0742 (PPAR $\beta$ agonist; Sigma-Aldrich), and rosiglitazone (PPAR $\gamma$ agonist; SigmaAldrich) in the presence or absence of the antagonists GW7467 (PPAR $\alpha$ antagonist; Sigma-Aldrich), GW0742 (PPAR $\beta$ antagonist; Sigma-Aldrich) and GW9662 (PPAR $\gamma$ antagonist; Sigma-Aldrich) for 24 hours. Each treatment was performed in triplicate for each preparation of cells.

\section{Total RNA Extraction and Quantitative Real-Time RT-PCR}

Total RNA extraction and quantitative real-time RT-PCR were performed as described previously. ${ }^{31,32}$ Briefly, total RNA was prepared from chorionic tissues and cells by using TRIzol reagent (Invitrogen Corp.). Two micrograms of RNA was reverse transcribed with oligo(dT)18 primer by using the Moloney Murine Leukemia Virus Reverse Transcriptase (Promega, Madison, WI) and then stored at $-20^{\circ} \mathrm{C}$. Specific primers for the amplification of PGDH were as follows: sense, $5^{\prime}$-TTGCACAGCAGCCGGTTTAT- $3^{\prime}$ and antisense, 5'-TTGGCAATCAATGGTGGGTC-3' (GenBank; http://www.ncbi.nlm.nih.gov/genbank, accession number NM_000860). Quantitative real-time PCR was performed with Rotor-Gene 3000 (Corbett Research, Sydney, $\mathrm{NSW}$, Australia). The reaction solution consisted of $2.0 \mu \mathrm{L}$ of diluted cDNA, $0.2 \mu \mathrm{mol} / \mathrm{L}$ of each paired primer, $200 \mu \mathrm{mol} / \mathrm{L}$ deoxynucleotide triphosphates, and $1 \times$ PCR Master Mix (TaKaRa, Otsu, Japan). SYBR Green (F Hoffmann-La Roche Ltd, Basel, Switzerland) was used as detection dye. The annealing temperature was set at $60^{\circ} \mathrm{C}$, and amplification cycles were set at 40 cycles. The temperature range to detect the melting temperature of the PCR product was set from $60^{\circ} \mathrm{C}$ to $95^{\circ} \mathrm{C}$. Amplification of the housekeeping genes $\beta$-actin and GAPDH were measured for each sample as an internal control for sample loading and normalization. The relative expression of PGDH was determined by using comparative threshold cycle method. ${ }^{33}$ Because similar data were obtained by using either of $\beta$-actin and GAPDH genes as an internal control, $\beta$-actin gene was used for presentation of the results.

\section{Western Blot Analysis}

Chorionic tissues or cells were homogenized in RIPA lysis buffer that contained phosphatase inhibitor cocktail (Roche, Indianapolis, IN). Proteins $(50 \mu \mathrm{g})$ were denatured and separated by $12 \%$ SDS-PAGE and subsequently transferred to nitrocellulose membranes by electroblotting. After transfer, membranes were incubated in blocking buffer, then with the specific antibodies (dilution 1:200 to 1:300) against PPAR $\alpha$, PPAR $\beta$, PPAR $\gamma$, RXR $\alpha$ (sc-553; Santa Cruz Biotechnology), PGDH (160615; Cayman Chemical, Ann Arbor, MI), $\beta$-actin (Sigma-Aldrich), or GAPDH (Sigma-Aldrich) at $4^{\circ} \mathrm{C}$ overnight, then followed by incubation with a secondary horseradish peroxidase-conjugated IgG (dilution 1:1000). Immunoreactive proteins were visualized with the enhanced chemiluminescence Western blot detection system (Santa Cruz Biotechnology). The intensities of light-emitting bands were detected and quantified with the Sygene Bio Image system (Synoptics Ltd, Cambridge, UK). To control sampling errors, the ratio of band intensities to $\beta$-actin or GAPDH was obtained to quantify the relative protein expression level. Because almost the same results for relative expression of PPAR $\alpha, \operatorname{PPAR} \beta, \operatorname{PPAR} \gamma$, or PGDH were obtained with either $\beta$-actin or GAPDH as the internal control (Supplemental Figure S1), $\beta$-actin was therefore used for presentation of the results.

\section{PGDH Activity Assay}

PGDH activity was assayed by measuring 13,14-dihydro-15keto PGF2, the stable metabolite of PGF2. 13,14-Dihydro15-keto PGF2 content in culture medium was determined by using a commercial PGFM EIA kit (Cayman Chemical) as described previously. ${ }^{28}$ The standard curve ranged from 1000 $\mathrm{pg} / \mathrm{mL}$ to approximately $7.81 \mathrm{pg} / \mathrm{mL}$.

\section{RNA Interferences}

Sequence-specific siRNAs that targeted human PPAR $\alpha$ (sense, 5'-GGGUUUAUAACUCGUGAAUTT-3'; antisense, 5'-AUUCACGAGUUAUAAACCCTT-3'), PPAR $\beta$ (sense, $5^{\prime}$-CCCUAUUCAUUGCGGCCAUTT- ${ }^{\prime}$; antisense, $5^{\prime}$-AUGGCCGCAAUGAAUAGGGTT-3'), PPAR $\gamma$ (sense, $5^{\prime}$-CUGGCCUCCUUGAUGAAUATT- $3^{\prime}$; antisense, $5^{\prime}$-UAUUCAUCAAGGAGGCCAGTT- $3^{\prime}$ ), and RXR $\alpha$ (sense, $5^{\prime}$-AGGACUGCCUGAUUGACAATT- $3^{\prime}$; antisense, 5'-UUGUCAAUCAGGCAGUCCUTG- $3^{\prime}$ ) were used. The following siRNA (sense, $5^{\prime}$-UUCUCCGAACGUGUCACGUTT- ${ }^{\prime}$, and antisense, $5^{\prime}$-ACGUGACACGUUCGGAGAATT- $3^{\prime}$ ) were used as a control. On the second day of plating, chorionic trophoblasts were transfected with the above siRNA by using Lipofectamine 2000 (Invitrogen Corp.).

\section{Assessment of de Novo Protein Synthesis Involvement}

Trophoblasts cells were pretreated with the translational inhibitor cycloheximide (Sigma-Aldrich) at $10^{-5} \mathrm{~mol} / \mathrm{L}$, for 1 hour before the addition of $10^{-6} \mathrm{~mol} / \mathrm{L} \mathrm{GW} 7647,10^{-6}$ $\mathrm{mol} / \mathrm{L}$ GW0742, and $10^{-6} \mathrm{~mol} / \mathrm{L}$ rosiglitazone. At the end of 24 hours of treatment, the cells were harvested for RNA isolation and real-time RT-PCR analysis.

\section{Assessment of PGDH mRNA Stability}

The trophoblast cells were treated with $10^{-6} \mathrm{~mol} / \mathrm{L}$ GW7647, $10^{-6} \mathrm{~mol} / \mathrm{L} \mathrm{GW} 0742$, and $10^{-6} \mathrm{~mol} / \mathrm{L}$ rosiglitazone for 12 hours. Transcription was then stopped with 25 $\mu \mathrm{mol} / \mathrm{L} \quad 5,6$-dichloro-1- $\beta$-D-ribofuranosylbenzimidazole (Sigma-Aldrich), and cells were harvested at discrete times 
Table 1 Characteristics of Study Participants in the TNL, TL, and PTL Groups

\begin{tabular}{|c|c|c|c|c|}
\hline \multirow[b]{2}{*}{ Clinical feature } & \multirow[b]{2}{*}{$\operatorname{TNL}(n=24)$} & \multirow[b]{2}{*}{$\mathrm{TL}(n=24)$} & \multicolumn{2}{|l|}{$\mathrm{PL}$} \\
\hline & & & Without CAM $(n=16)$ & $\operatorname{CAM}(n=8)$ \\
\hline $\begin{array}{l}\text { Weeks of gestation, means } \pm \text { SEM } \\
\text { Labor status, } \%(n / N)\end{array}$ & $39.09 \pm 0.99$ & $40.12 \pm 1.23$ & $34.19 \pm 0.14^{* *}$ & $34.23 \pm 0.55^{* *}$ \\
\hline Spontaneous & & $100(24 / 24)$ & $100(16 / 16)$ & $100(8 / 8)$ \\
\hline Induced & & 0 & 0 & 0 \\
\hline \multicolumn{5}{|l|}{ Delivery mode } \\
\hline \multicolumn{5}{|l|}{ Membrane rupture, $\%(n / N)$} \\
\hline SPOM & & $62.5(15 / 24)$ & & \\
\hline PROM & & & $81.2(13 / 16)$ & $100(8 / 8)$ \\
\hline ARM & $100(24 / 24)$ & $37.5(9 / 24)$ & $18.8(3 / 16)$ & \\
\hline Fetal weight, means \pm SEM, g & $3467.29 \pm 81.85$ & $3354.88 \pm 62.08$ & $2374.69 \pm 111.02 * *$ & $2394.38 \pm 175.04^{* *}$ \\
\hline
\end{tabular}

${ }^{*} P<0.05$ and ${ }^{*} P P<0.01$ between TL and PTL, respectively.

ARM, artificial rupture of membranes, either during or at abdominal delivery; PROM, prelabor rupture of membranes; PTL, preterm labor; SROM, spontaneous rupture of membranes with labor; TNL, term no labor; TL, term labor.

(0 to 12 hours) thereafter for RNA isolation and real-time RT-PCR analysis as described previously. ${ }^{34}$

\section{Determination of HPGD Promoter Activity}

On the second day of plating, trophoblasts were transfected with $0.5 \mu \mathrm{g} /$ well $\mathrm{PGL}_{3}$-luciferase reporter plasmids carrying HPGD ( -2368 upstream to the transcription start site) promoter (gift from Dr. Birgit Gellersen, IHF Institute for Hormone and Fertility Research, Hamburg, Germany) and $50 \mathrm{ng}$ of control DNA (pRL-TK-Renilla-luciferase vector; Promega) by using Lipofectamine 2000. Cells were then treated with various reagents as indicated. Luciferase assays were performed 24 hours later by using the dual luciferase assay kit (Promega). Relative luciferase activity is presented as firefly luciferase values normalized to renilla luciferase activity.

\section{Statistical Analysis}

All results are presented as means \pm SEM. All data were tested for homogeneity of variance by Kolmogorov-Smirnov test. The data of chorionic tissues from TNL, TL, and PTL women were not normally distributed. Nonparametric tests of significance were therefore used in the analysis of the data of chorionic tissues. Individual comparisons were made by oneway analysis of variance followed by the Student-NewmanKeuls test for the data which were normally distributed. Significance was set at $P<0.05$.

\section{Results}

\section{Clinical Characteristics of the Patients}

The clinical characteristics for the patients included in this study are shown in Table 1 . In the TL group, the women all went into spontaneous labor and delivered vaginally, and $62.5 \%$ of the women had spontaneous rupture of the fetal membranes with labor. Women undergoing induction of labor were excluded. In the PTL without CAM group, most of the women $(83 \%)$ had prelabor rupture of membranes, whereas preterm women with CAM all had prelabor rupture of membranes. Fetal weight was substantially lower, and gestational age was substantially shorter in the PTL group with or without CAM.

\section{Localization of PPARs in Fetal Membranes}

Three PPARs, PPAR $\alpha$, PPAR $\beta$, and PPAR $\gamma$, were identified in chorion laeve and amnion (Figure 1 and Supplemental Figure S2). In chorion, all of the PPARs predominantly localized to trophoblasts. The positive staining was observed in either plasma or nucleus of the trophoblasts (Figure 1). In amnion, the positive staining of three PPARs was predominantly located in epithelial cells (Supplemental Figure S2).

\section{Expression of PGDH and PPARs in Chorionic Tissues at TL and PTL}

The expression level of PGDH protein was significantly down-regulated in the TL group compared with the TNL group $(P<0.01)$ (Figure $2 \mathrm{~A})$. In preterm birth, no matter with or without CAM, the amount of PGDH was significantly lower than in the TNL group. PGDH expression was lower in the PTL group than in the TL group, with no significance. No substantial difference was found in PGDH expression between PTL with CAM and without CAM.

PPAR $\beta$ and PPAR $\gamma$ expression was significantly decreased with labor $(P<0.01$ TL group versus TNL group), whereas $\operatorname{PPAR} \alpha$ remained unchanged with labor (Figure 2, B-D). PGDH amount positively correlated with PPAR $\alpha, \operatorname{PPAR} \beta$, 

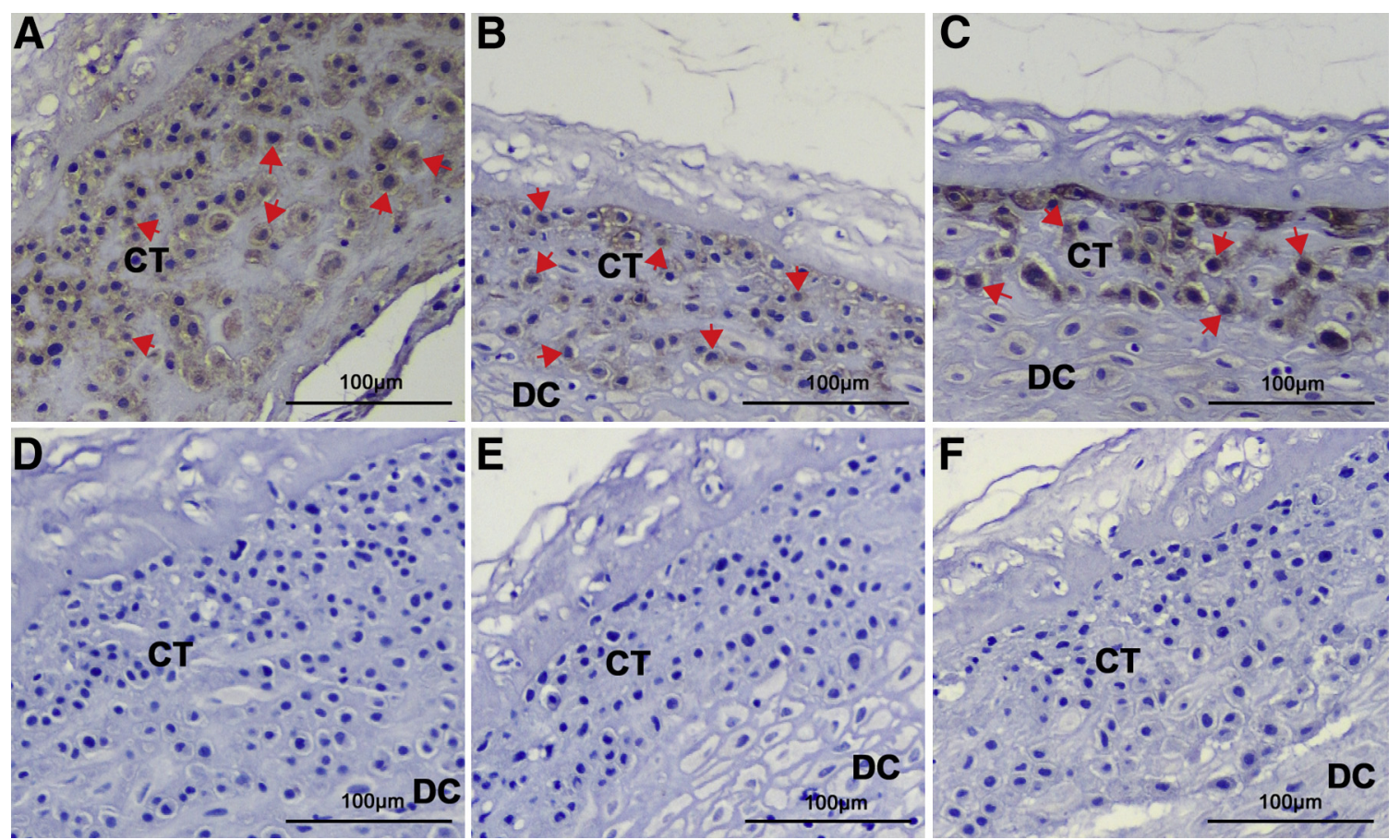

Figure 1 Localization of PPARs in human chorion. A-C: Immunohistochemistry analysis shows representative sections for positive staining for PPAR $\alpha$ (A), PPAR $\beta$ (B), and PPAR $\gamma(\mathbf{C})$. D-F: Negative control sections that were performed with the primary antibodies preabsorbed with excess corresponding peptide. Negative control for PPAR $\alpha$ (D), PPAR $\beta(E)$, and PPAR $\gamma(\mathbf{F})$. Arrows indicate positive staining. Original magnification, $\times 200$. CT, chorionic trophoblast; $D C$, decidua; PPAR, peroxisome proliferator-activated receptor.

and PPAR $\gamma$ amount in TNL tissues (Figure 2, E-G), whereas it correlated to PPAR $\gamma$ but not to PPAR $\alpha$ and PPAR $\beta$ in TL tissues (Figure 2, H-J).

The amount of PPAR $\beta$ and PPAR $\gamma$ was significantly lower in PTL tissues than in the TNL group but was comparable with that in the TL group (Figure 2, C and D). The amount of PPAR $\beta$ in the PTL with CAM group was significantly higher than in the TL group $(P<0.05)$ (Figure $2 \mathrm{C}$ ). No significant difference in PPAR $\alpha$ expression was found among the PTL and TL groups (Figure 2B). The amount of PPAR $\alpha$ was lower in PTL with CAM than in TNL tissues $(P<0.05)$. No correlation was found between PGDH and PPARs in PTL tissues (data not shown).

PPARs Stimulate PGDH Expression and Activity in Cultured Chorionic Trophoblasts

We then examined whether activation of PPARs affects PGDH expression in chorionic trophoblasts. Treatment of cultured trophoblasts with increasing concentration of PPAR $\alpha$ agonist GW7647 $\left(10^{-9}\right.$ to $\left.10^{-6} \mathrm{~mol} / \mathrm{L}\right)$ for 24 hours caused an increase in PGDH mRNA and protein expression and PGDH activity in a dose-dependent manner (Figure 3, A and B). The effect of GW7647 on PGDH could be blocked by PPAR $\alpha$ antagonist GW6471. Treatment of cells with PPAR $\beta$ and PPAR $\gamma$ agonists also dose dependently increased PGDH mRNA and protein expression and PGDH activity. Their effects were reversed by the specific antagonists (Figure 3, D, E, G, and H).
To confirm the role of PPARs, siRNA targeting PPARs approach was applied. Transfection of PPAR $\alpha, \operatorname{PPAR} \beta$, and PPAR $\gamma$ siRNA into cells resulted in $73.2 \%, 71.5 \%$, and $88 \%$ reduction in PPAR $\alpha, \operatorname{PPAR} \beta$, and PPAR $\gamma$ (Supplemental Figure S3, A-C), respectively. Treatment of these cells with GW7647, GW0742, and rosiglitazone did not affect PGDH expression (Figure 3, C, F, and I).

Classically, PPARs exert their effects by forming obligate heterodimers with the RXRs. ${ }^{28}$ In chorion, the RXR $\alpha$ is the predominant subtype of RXRs. ${ }^{35,36}$ To confirm this, the expression of RXR $\alpha$ in chorion was examined. It was found that $\operatorname{RXR} \alpha$ was expressed in chorionic tissues and cultured chorionic cells (Supplemental Figure S4). Thus, we investigated the effect of $\mathrm{RXR} \alpha$ ligand 9-cis-retinoid acid on GW7647, GW0742, and rosiglitazone modulation of PGDH expression. 9-cis-Retinoid acid alone increased PGDH expression (Figure 4). Moreover, 9-cis-retinoid acid $\left(10^{-7} \mathrm{~mol} /\right.$ L) enhanced the stimulatory effect of GW76747, GW0742, and rosiglitazone on PGDH expression. We further confirmed the role of RXR $\alpha$ by using siRNA approach. Transfection of siRNA that targeted RXR $\alpha$ resulted in $76.9 \%$ reduction in RXR $\alpha$ expression (Supplemental Figure S3D), which caused a loss of PPARs agonist-induced PGDH expression.

\section{PPARs Induce PGDH Expression through Gene Transcription}

To determine whether the PPAR-induced increase in PGDH expression required de novo protein synthesis, trophoblast 

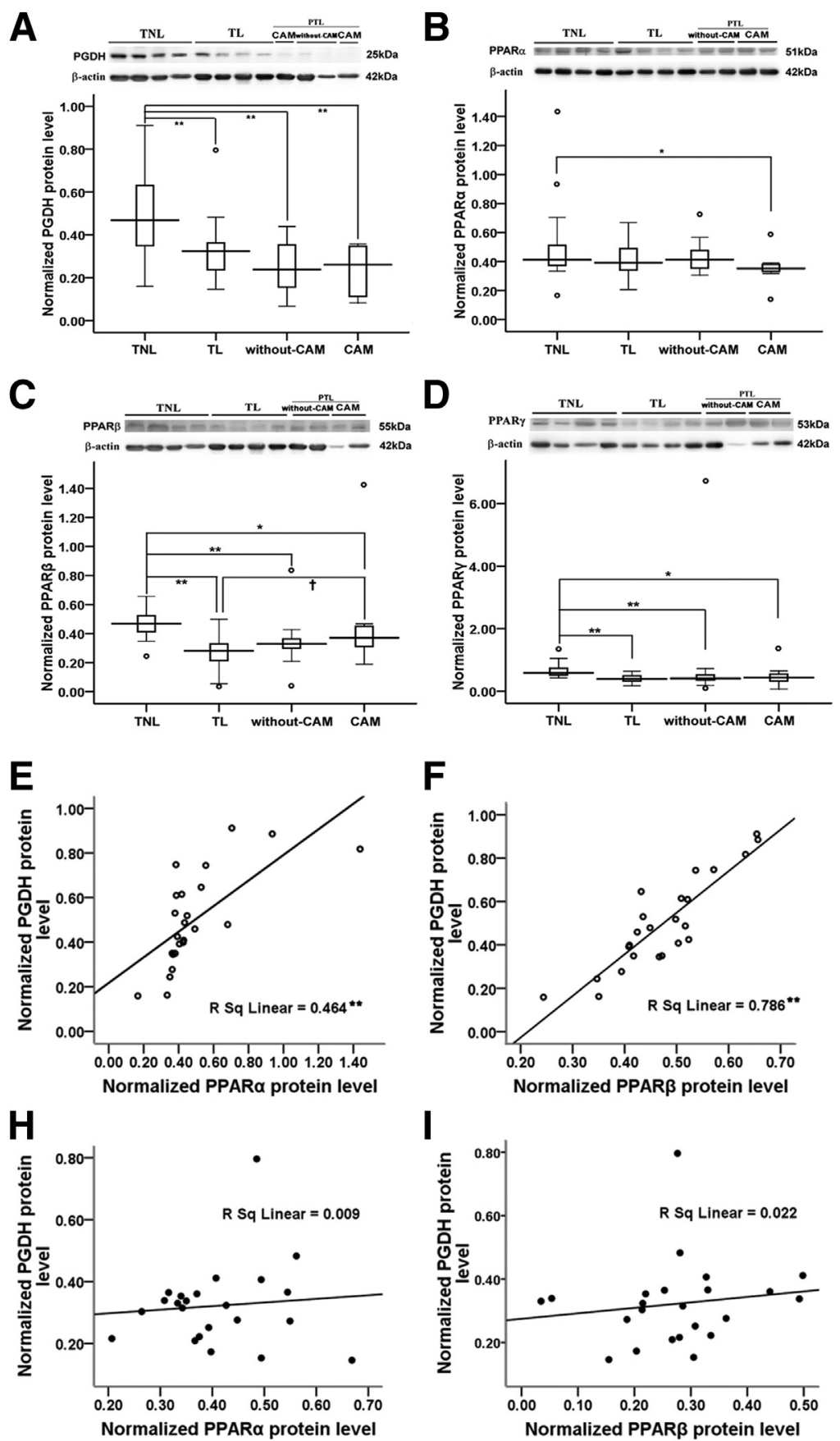

Figure 2 The expression of $\mathrm{PGDH}$, PPAR $\alpha$, PPAR $\beta$, and PPAR $\gamma$ and the correlation between $11 \beta-H S D 2$ and PPAR $\alpha$, PPAR $\beta$, or PPAR $\gamma$ in TL, TNL, and PTL chorionic tissues. $\mathbf{A}-\mathbf{D}$ : The protein expression of $11 \beta-H S D 2$, PPAR $\alpha$, PPAR $\beta$, and PPAR $\gamma$ in TL, TNL, and PTL chorionic tissues. Representative protein bands are presented on the top of corresponding histogram. E-G: The correlation between PGDH and PPAR $\alpha$, PPAR $\beta$, or PPAR $\gamma$ in TNL tissues. $\mathbf{H}-\mathbf{J}$ : The correlation between PGDH and PPAR $\alpha$, PPAR $\beta$, or PPAR $\gamma$ in TL tissues. ${ }^{*} P<0.05$, $* * P<0.01$ versus TNL; ${ }^{\dagger} P<0.05$ versus TL. CAM, chorioamnionitis; PGDH, 15hydroxyprostaglandin dehydrogenase; PPAR, peroxisome proliferator-activated receptor; PTL, preterm labor; TNL, term no labor; TL, term labor; $11 \beta-H S D 2,11 \beta$ hydroxysteroid dehydrogenase type 2 .

G
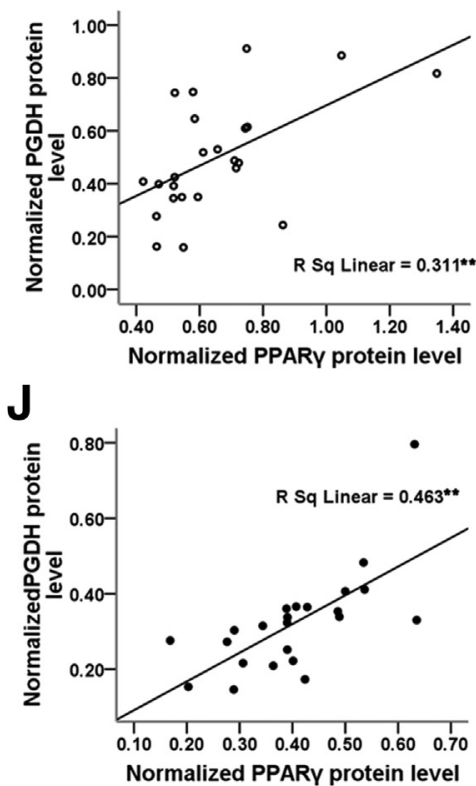

cells were treated with GW7647, GW0742, and rosiglitazone in the absence and presence of $10^{-5} \mathrm{~mol} / \mathrm{L}$ cycloheximide, a protein synthesis inhibitor. The results showed that GW7647, GW0742, and rosiglitazone were equally effective in modulating PGDH mRNA in the absence and presence of cycloheximide, suggesting that de novo protein synthesis was not required (Figure 5A).

We then assessed the half-life of PGDH mRNA by a standard mRNA decay assay by using $25 \mu \mathrm{mol} / \mathrm{L}$ of $5,6-$ dichloro-1- $\beta$-D-ribofuranosylbenzimidazole, an inhibitor of mRNA synthesis. GW7647, GW0742, and rosiglitazone did not alter the half-life of PGDH mRNA (Figure 5B).
The effects of GW7647, GW0742, and rosiglitazone on the rate of $H P G D$ gene transcription were then determined. The trophoblasts were transiently transfected with a luciferase construct that contained a series of $5^{\prime}$-deletion mutants from the 2.4-kb 5'-flanking region of the HPGD gene. GW7647, GW0742, and rosiglitazone stimulated $H P G D$ promoter activity (Figure 5C).

\section{Discussion}

We showed that three PPARs are expressed in chorionic trophoblasts and amnion epithelium. Three PPARs stimulate 

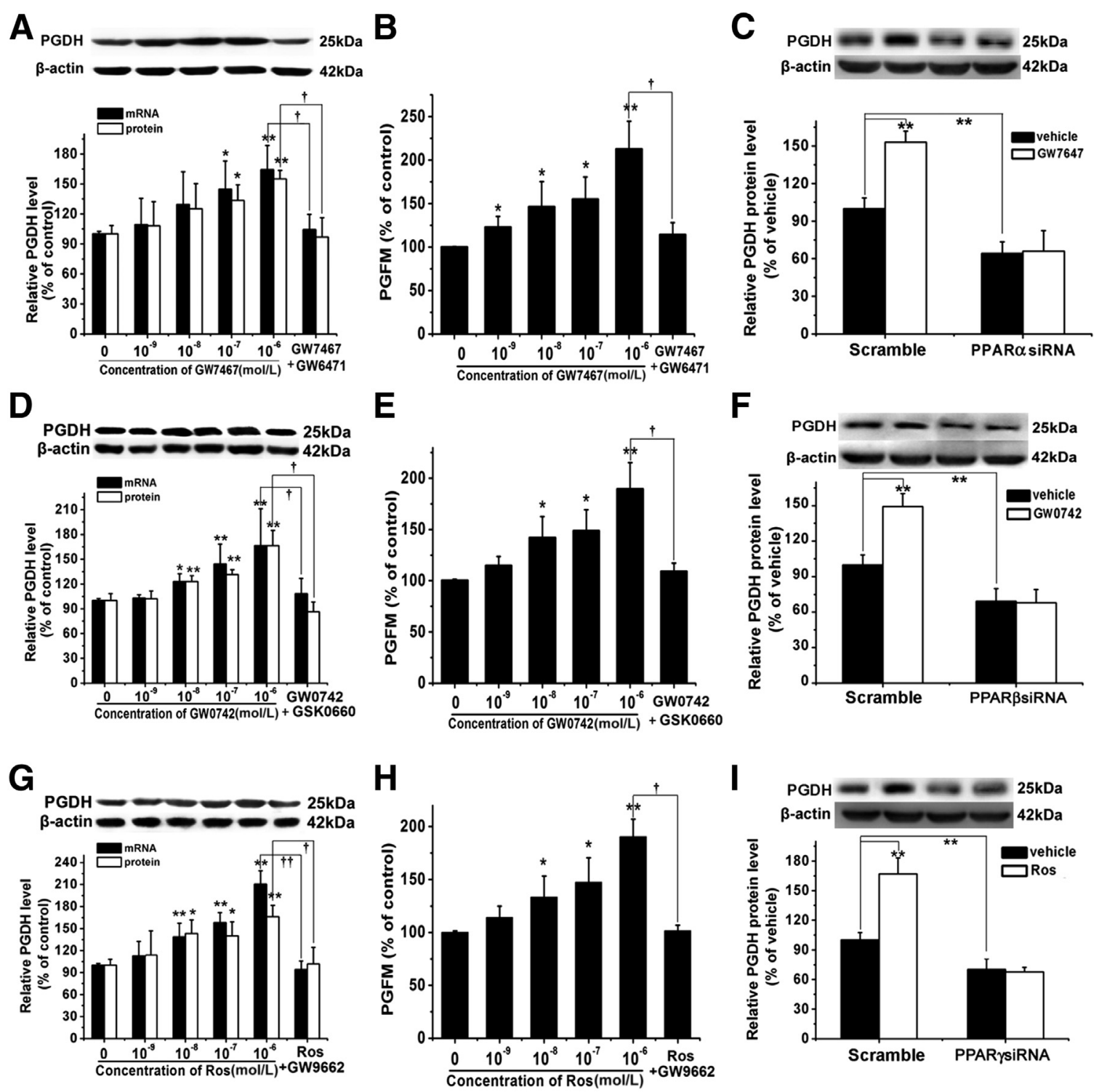

Figure 3 Effects of PPARs on PGDH expression and activity in cultured chorionic trophoblast cells. A and B: The effect of PPAR $\alpha$ agonist on PGDH expression and activity. Cells were treated with PPAR $\alpha$ agonist GW7647 $\left(10^{-9}\right.$ to $\left.10^{-6} \mathrm{~mol} / \mathrm{L}\right)$ for 24 hours in the presence or absence of $10^{-6} \mathrm{~mol} / \mathrm{L}$ PPAR $\alpha$ antagonist GW6471. C: The effects of GW7647 on PGDH expression in PPAR $\alpha$ knockdown cells. Cells were transfected with PPAR $\alpha$ siRNA or scramble siRNA and then treated with $10^{-6} \mathrm{~mol} / \mathrm{L}$ GW7647 for 24 hours. D and E: The effect of PPAR $\beta$ agonist on PGDH expression and activity. Cells were treated with PPAR $\beta$ agonist GW0742 $\left(10^{-9}\right.$ to $\left.10^{-6} \mathrm{~mol} / \mathrm{L}\right)$ for 24 hours in the presence or absence of $10^{-6} \mathrm{~mol} / \mathrm{L}$ PPAR $\beta$ antagonist GSK0660. F: The effects of GW0742 on PGDH expression in PPAR $\beta$ knockdown cells. Cells were transfected with PPARß siRNA or scramble siRNA and then treated with $10^{-66} \mathrm{~mol} / \mathrm{L} \mathrm{GW} 0742 \mathrm{for} 24 \mathrm{hours}$. $\mathbf{G}$ and $\mathbf{H}$ : The effect of PPAR $\gamma$ agonist on PGDH expression and activity. Cells were treated with PPAR $\gamma$ agonist rosiglitazone $\left(10^{-9}\right.$ to $\left.10^{-6} \mathrm{~mol} / \mathrm{L}\right)$ for 24 hours in the presence or absence of $10^{-6} \mathrm{~mol} / \mathrm{L}$ PPAR $\gamma$ antagonist GW9662. I: The effects of rosiglitazone on PGDH expression in PPAR $\gamma$ knockdown cells. Cells were transfected with PPAR $\gamma$ SiRNA or scramble siRNA and then treated with $10^{-6} \mathrm{~mol} / \mathrm{L}$ rosiglitazone for 24 hours. PGDH expression and activity were determined by real-time RT-PCR, Western blot analysis, and radiometric conversion assay, respectively. Representative protein bands are presented on the top of corresponding histogram. Data are expressed as mean percentage of control \pm SEM of five cultures $(n=4)$ performed in triplicate. ${ }^{*} P<0.05$, ${ }^{* *} P<0.01$ versus vehicle control; ${ }^{\dagger} P<0.05,{ }^{\dagger \dagger} P<0.01$ versus corresponding agonist. PGDH, phosphogluconate dehydrogenase; PPAR, peroxisome proliferator-activated receptor; Ros, rosiglitazone.

PGDH expression and activity in chorionic trophoblasts, which require RXR $\alpha$. The stimulatory effect of PPARs on PGDH expression is through up-regulation of transcriptional activity of the HPGD gene. The PGDH amount in chorion is associated with decreased expression of PPAR $\gamma$ in TL but not in PTL.

The expression of PPARs in human fetal membranes with labor at term in previous studies is controversial. HoldsworthCarson et $\mathrm{al}^{26}$ recruited smaller samples of human fetal membranes from pregnant women with or without labor at term ( $n=6$ to 7 in each group) and showed that protein amounts of PPARs are not changed in fetal membranes with labor at term, although PPAR $\beta$ mRNA expression increased with labor in choriodecidua, which were obtained from smaller samples of human fetal membranes. Berry et $\mathrm{al}^{21}$ have demonstrated the data from relative larger samples $(n=15$ in each group) that PPAR $\alpha$ mRNA in choriodecidua decreases 

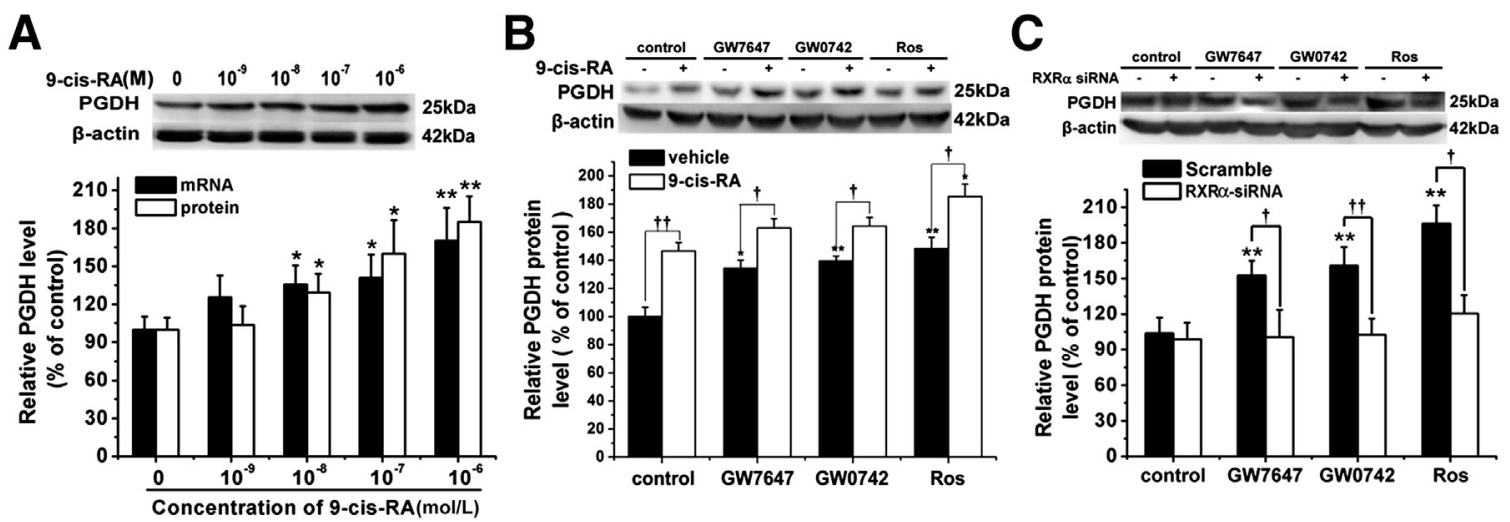

Figure 4 The role of RXR $\alpha$ in PPARs modulation of PGDH expression in cultured chorionic trophoblasts. A: Cells were treated with RXR $\alpha$ agonist 9-cis-RA $\left(10^{-9}\right.$ to $\left.10^{-6} \mathrm{~mol} / \mathrm{L}\right)$ for 24 hours. B: Cells were treated with $10^{-6} \mathrm{~mol} / \mathrm{L} \mathrm{PPAR} \alpha$ agonist GW7647, $10^{-6} \mathrm{~mol} / \mathrm{L}$ PPAR $\beta$ agonist GW0742, and $10^{-6} \mathrm{~mol} / \mathrm{L}$ Ros for 24 hours in the presence or absence of $10^{-7} \mathrm{~mol} / \mathrm{L}$ 9-cis-RA. C: The effects of GW7647, GW0742, and Ros on 11ß-HSD2 expression in RXR $\alpha$ knockdown cells.

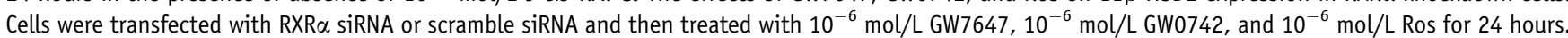
PGDH mRNA and protein expression were determined by real-time RT-PCR and Western blot analysis, respectively. Representative protein bands are presented on the top of corresponding histogram. Values are expressed as means \pm SEM. $n=4$. ${ }^{*} P<0.05,{ }^{*} P<0.01$ versus control; ${ }^{\dagger} P<0.05,{ }^{\dagger \dagger} P<0.01$ versus vehicle or transfected with scramble siRNA. RXR, retinoid $X$ receptor; PGDH, phosphogluconate dehydrogenase; PPAR, peroxisome proliferator-activated re-

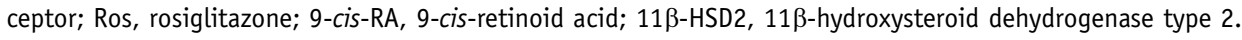

after onset of labor. Dunn-Albanese et $\mathrm{al}^{37}$ reported that the protein amount of PPAR $\gamma$ significantly decreases in fetal membranes with labor at term, but they did not distinguish the amount of PPAR $\gamma$ in amnion and choriodecidua. Here, we recruited more patients $(n=24$ in each group) and found that PPAR $\gamma$ and PPAR $\beta$ protein expression significantly decreased in chorion laeve with labor at term. Studies about the expression of PPARs in gestational tissues in PTL are few. Holdsworth-Carson et $\mathrm{al}^{27}$ have shown that PPAR $\beta$ protein expression in choriodecidua is higher in the PTL group than in the TL group, whereas the amount of PPAR $\alpha$ and PPAR $\gamma$ is not different between the PTL and TL groups. Consistently, we showed that the PPAR $\beta$ amount was higher in the PTL with CAM group than in the TL group, whereas its amount in the PTL without CAM group was not different with that in the TL group. In addition, PPAR $\alpha$ and PPAR $\gamma$ expressions do not significantly differ between the PTL and TL groups. However, with the use of TNL as the control, the expression of PPAR $\beta$ and PPAR $\gamma$ decreased in PTL. Because it is hard to get the gestational age-matched samples of preterm not in labor, it remains uncertain whether the amount of PPARs changes with labor at preterm.

A few studies have found that PPARs modulate the production of inflammatory mediators in amnion; in particular, PPAR $\gamma$ exhibits an inhibitory effect on the production of a number of proinflammatory cytokines, including IL-1, IL-6, and tumor necrosis factor- $\alpha$ and cytokine-induced PG H synthase-2 expression. ${ }^{22,38-40}$ Dunn-Albanese et $\mathrm{al}^{37}$ reported that the ratio of cyclooxygenase-2/PPAR $\gamma$ expression significantly increased after labor, consequently the local amount of PGs increased in fetal membranes. They therefore implicated that PPAR $\gamma$ might modulate the production of
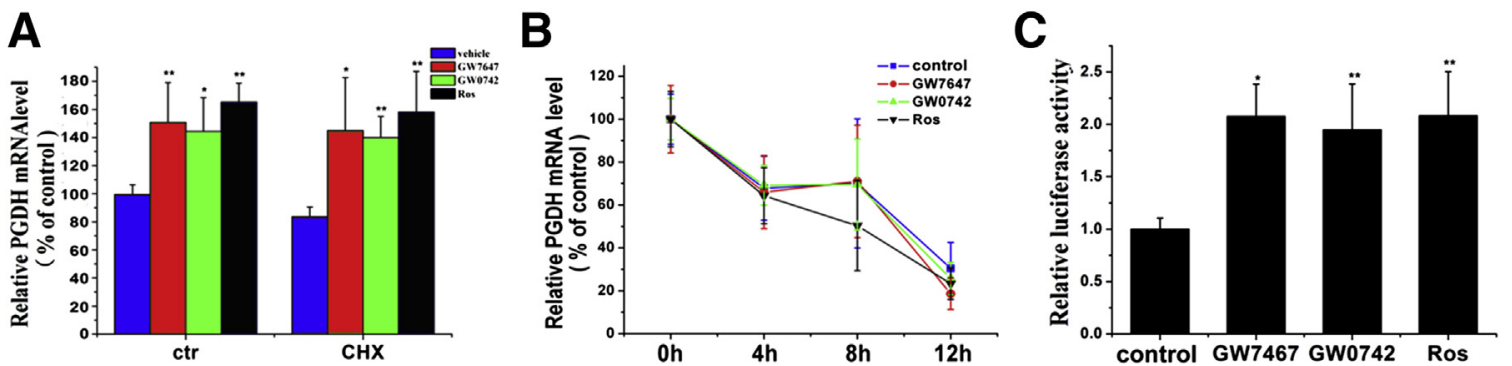

Figure 5 The effects of protein inhibitors on PPAR-induced alternation of PGDH expression and the effects of PPARs on PGDH gene transcription in cultured chorionic trophoblasts. A: The effect of protein inhibitor CHX on PPAR $\alpha-$, PPAR $\beta$-, and PPAR $\gamma$-induced alternation of PGDH. Trophoblasts were

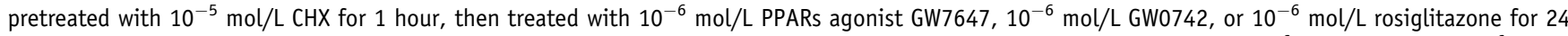

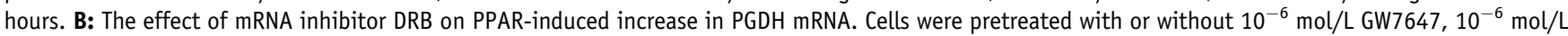
GW0742, or $10^{-6} \mathrm{~mol} / \mathrm{L}$ Ros for 12 hours. The cells were then treated with $25 \mu \mathrm{mol} / \mathrm{L}$ DRB in the absence or presence of the above reagents (defined as time 0 ). At the indicated time points thereafter, total cellular RNA was isolated, and the steady state amount of mRNA was assayed by real-time RT-PCR. C: The effect of

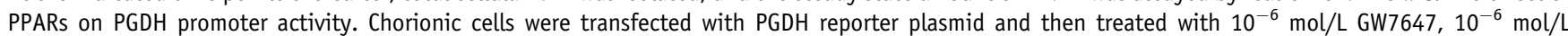
GW0742, or $10^{-6} \mathrm{~mol} / \mathrm{L}$ Ros for 24 hours. Values are expressed as means \pm SEM. $n=3 .{ }^{*} P<0.05,{ }^{*} P<0.01$ versus control. CHX, cycloheximide; DRB, 5,6dichloro-1- $\beta$-D-ribofuranosylbenzimidazole; PGDH, phosphogluconate dehydrogenase; PPAR, peroxisome proliferator-activated receptor; Ros, rosiglitazone. 
PGs in fetal membranes. Our findings that PPARs stimulate PGDH expression in chorion indicate that PPARs are the regulators for PGs output in fetal membranes. It is known that PPARs can be activated by arachidonic acid, eicosanoids, and PG metabolites such as, PGD2, PGJ2, and 15hydroxyeicosatetraenoic acid. ${ }^{40}$ Taken together, it indicates that reciprocal modulation between PPARs and PGs might occur in fetal membranes.

Here, we also found that PGDH expression positively correlated to three types of PPARs in chorion at term before onset of labor. As mentioned, PPARs could increase PGDH expression in chorionic trophoblasts, suggesting that PPARs play an important role in the maintenance of PGDH expression in chorion throughout gestation, which would help to maintain a lower amount of active PGs in myometrium during pregnancy. After onset of labor, PGDH expression reduces, with a coincident decrease of PPAR $\beta$ and PPAR $\gamma$ expression; PGDH correlated to the PPAR $\gamma$ expression level. Thus, decreased PPAR $\gamma$ may, at least in part, contribute to the reduction of PGDH expression in chorion at term after onset of labor. Note that PGDH expression did not correlate to PPAR $\beta$ amount in TL tissues, although PPAR $\beta$ expression decreased with labor. PGDH expression not only depends on the expression level of PPARs but also depends on the active state of PPARs in vivo. PPARs are activated by various intrinsic ligands as mentioned. Thus, the changed concentration of ligands can influence the activity of PPARs and may subsequently affect the expression of PGDH. Moreover, our data showed that the amount of PGDH did not correlate to PPARs, although the amount of PPAR $\beta$ and PPAR $\gamma$ in chorion was lower in the PTL group than that in the TNL group, suggesting that regulation of PGDH expression by PPARs might not be the case in PTL. Previous studies have found that proinflammatory cytokines, such as IL-1, suppress PGDH expression in chorionic trophoblasts, to likely reduce PGDH expression in the case of PTL. ${ }^{41,42}$ Although it is possible that PPARs and concentration of ligands might be involved, our study may suggest that regulatory mechanisms of PGDH in chorion might be different in the case of TL and PTL.

\section{Conclusions}

PPAR $\alpha$, PPAR $\beta$, and PPAR $\gamma$ enhance PGDH expression in human chorionic trophoblasts. PPARs might be the important factors in maintenance of PGDH expression in chorion during pregnancy. Decreased PGDH expression in labor is associated with changed expression of PPARs during labor at term.

\section{Acknowledgments}

We thank the nursing and medical staff of the delivery suite and the patients at Changhai Hospital (Shanghai, China) and Maternity and Child Health Hospital of Pudong New
District (Shanghai, China) for their participation. $\mathrm{PGL}_{3}-$ luciferase reporter plasmids were a gift from Dr. Birgit Gellersen (IHF Institute for Hormone and Fertility Research, Hamburg, Germany).

\section{Supplemental Data}

Supplemental material for this article can be found at http://dx.doi.org/10.1016/j.ajpath.2015.03.021.

\section{References}

1. Challis JR, Lye SJ, Gibb W: Prostaglandins and parturition. Ann N Y Acad Sci 1997, 828:254-267

2. Thorburn GD: The placenta, PGE2 and parturition. Early Hum Dev 1992, 29:63-73

3. Lundin-Schiller S, Mitchell MD: The role of prostaglandins in human parturition. Prostaglandins Leukot Essent Fatty Acids 1990, 39:1-10

4. Olson DM: The role of prostaglandins in the initiation of parturition. Best Pract Res Clin Obstet Gynaecol 2003, 17:717-730

5. Teixeira FJ, Zakar T, Hirst JJ, Guo F, Sadowsky DW, Machin G, Demianczuk N, Resch B, Olson DM: Prostaglandin endoperoxide-H synthase (PGHS) activity and immuoreactive PGHS-1 and PGHS-2 levels in human amnion throughout gestation, at term, and during labor. J Clin Endocrinol Metab 1994, 78:1396-1402

6. Gibb W, Sun M: Localization of prostaglandin H synthase type 2 protein and mRNA in term fetal membranes and deciduas. J Endocrinol 1996, 150:497-503

7. Nagai K, Tsuruta K, Mori N: Purification of an NAD+-dependent 15 hydroxyprostaglandin dehydrogenase from the human placenta. Prostaglandins Leukot Med 1987, 26:123-132

8. Okita RT, Okita JR: Prostaglandin-metabolizing enzymes during pregnancy: characterization of NAD+-dependent prostaglandin dehydrogenase, carbonyl reductase, and cytochrome P450-dependent prostaglandin omega-hydroxylase. Crit Rev Biochem Mol Biol 1996, $31: 101-126$

9. Cheung PY, Walton JC, Tai HH, Riley SC, Challis JR: Localization of 15-hydroxy prostaglandin dehydrogenase in human fetal membranes, decidua, and placenta during pregnancy. Gynecol Obstet Invest 1992, 33:142-146

10. Johnson RE, Mitchell CM, Clifton V, Zakar T: Regulation of 15hydroxyprostaglandin dehydrogenase (PGDH) gene activity, messenger ribonucleic acid processing, and protein abundance in the human chorion in late gestation and labor. J Clin Endocrinol Metab 2004, 89:5639-5648

11. Sangha RK, Walton JC, Ensor CM, Tai HH, Challis JR: Immunohistochemical localization, messenger ribonucleic acid abundance, and activity of 15-hydroxyprostaglandin dehydrogenase in placenta and fetal membranes during term and preterm labor. J Clin Endocrinol Metab 1994, 78:982-989

12. van Meir CA, Matthews SG, Keirse MJ, Ramirez MM, Bocking A, Challis JR: 15-Hydroxyprostaglandin dehydrogenase: implications in preterm labor with and without ascending infection. J Clin Endocrinol Metab 1997, 82:969-976

13. Germain AM, Smith J, Casey ML, MacDonald PC: Human fetal membrane contribution to the prevention of parturition: uterotonin degradation. J Clin Endocrinol Metab 1994, 78:463-470

14. Van Meir CA, Sangha RK, Walton JC, Matthews SG, Keirse MJ, Challis JR: Immunoreactive 15-hydroxyprostaglandin dehydrogenase (PGDH) is reduced in fetal membranes from patients at preterm delivery in the presence of infection. Placenta 1996, 17:291-297

15. Mitchell MD, Goodwin V, Mesnage S, Keelan JA: Cytokine-induced coordinate expression of enzymes of prostaglandin biosynthesis and 
metabolism: 15-hydroxyprostaglandin dehydrogenase. Prostaglandin Leukot Essent Fatty Acids 2000, 62:1-5

16. Rizek RM, Watson CS, Keating S, Tai HH, Challis JR, Bocking AD: 15-Hydroxyprostaglandin dehydrogenase protein expression in human fetal membranes with and without subclinical inflammation. Reprod Sci 2007, 14:260-269

17. Patel FA, Funder JW, Challis JR: Mechanism of cortisol/progesterone antagonism in the regulation of 15-hydroxyprostaglandin dehydrogenase activity and messenger ribonucleic acid levels in human chorion and placental trophoblast cells at term. J Clin Endocrinol Metab 2003, 88:2922-2933

18. Patel FA, Challis JR: Cortisol/progesterone antagonism in regulation of 15-hydroxysteroid dehydrogenase activity and mRNA levels in human chorion and placental trophoblast cells at term. J Clin Endocrinol Metab 2002, 87:700-708

19. Lamers C, Schubert-Zsilavecz M, Merk D: Therapeutic modulators of peroxisome proliferator-activated receptors (PPAR): a patent review (2008-present). Expert Opin Ther Pat 2012, 22:803-841

20. Yessoufou A, Wahli W: Multifaceted roles of peroxisome proliferator activated receptors (PPARs) at the cellular and whole organism levels. Swiss Med Wkly 2010, 140:w13071

21. Berry EB, Eykholt R, Hellivell RJ, Gilmour RS, Mitchell MD, Marvin KW: Peroxisome proliferator-activated receptor isoform expression changes in human gestational tissues with labor at term. Mol Pharmacol 2003, 64:1586-1590

22. Lappas M, Permezel M, Georgiou HM, Rice GE: Regulation of proinflammatory cytokines in human gestational tissues by peroxisome proliferator-activated receptor-gamma: effect of 15-deoxy-Delta $(12,14)-\mathrm{PGJ}(2)$ and troglitazone. J Clin Endocrinol Metab 2002, 87: $4667-4672$

23. Fournier T, Therond P, Handschuh K, Tsatsaris V, Evain-Brion D: PPAR $\gamma$ and early human placental development. Curr Med Chem 2008, 5:3011-3024

24. Ding NZ, Teng CB, Ma H, Ni H, Ma XH, Xu LB, Yang ZM: Peroxisome proliferator-activated receptor delta expression and regulation in mouse uterus during embryo implantation and decidualization. Mol Reprod Dev 2003, 66:218-224

25. Froment P, Gizard F, Defever D, Staels B, Dupont J, Monget P: Peroxisome proliferator-activated receptors in reproductive tissues: from gametogenesis to parturition. J Endocrinol 2006, 189:199-209

26. Holdsworth-Carson SJ, Permezel M, Riley C, Rice GE, Lappas M: Peroxisome proliferator-activated receptors and retinoid $\mathrm{X}$ receptoralpha in term human gestational tissues: tissue specific and labourassociated changes. Placenta 2009, 30:176-186

27. Holdsworth-Carson SJ, Permezel M, Rice GE, Lappas M: Preterm and infection-driven preterm labor: the role of peroxisome proliferatoractivated receptors and retinoid X receptor. Reproduction 2009, 137 : $1007-1015$

28. Tan NS, Michalik L, Desvergne B, Wahli W: Multiple expression control mechanisms of peroxisome proliferator-activated receptors and their target genes. J Steroid Biochem Mol Biol 2005, 93:99-105
29. Kliman HJ, Nestler JE, Sermasi E, Sanger JM, Strauss JF 3rd: Purification, characterization, and in vitro differentiation of cytotrophoblasts from human term placentae. Endocrinology 1986, 118:1567-1582

30. Gao L, He P, Sha J, Liu C, Dai L, Hui N, Ni X: Corticotropin-releasing hormone receptor type 1 and type 2 mediate differential effects on 15 hydroxy prostaglandin dehydrogenase expression in cultured human chorion trophoblasts. Endocrinology 2007, 148:3645-3654

31. Li Y, He P, Sun Q, Liu J, Gao L, You X, Gu H, Ni X: Reduced expression of 15-hydroxy prostaglandindehydrogenase in chorion during labour is associated with decreased PRB and increased PRA and GR expression. Am J Pathol 2013, 182:1585-1594

32. You XJ, Xu C, Lu JQ, Zhu XY, Gao L, Cui XR, Li Y, Gu H, Ni X: Expression of cystathionine $\beta$-synthase and cystathionine $\gamma$-lyase in human pregnant myometrium and their roles in the control of uterine contractility. PLoS One 2011, 6:e23788

33. Livak KJ, Schmittgen TD: Analysis of relative gene expression data using real-time quantitative PCR and the 2-(Delta DeltaC(T)) method. Methods 2001, 25:402-408

34. He P, Chen S, Sun Q, Li Y, Gu H, Ni X: Reduced expression of $11 \beta-$ hydroxysteroid dehydrogenase type 2 in preeclamptic placentas is associated with decreased PPAR $\gamma$ but increased PPAR $\alpha$ expression. Endocrinology 2014, 155:299-309

35. Guibourdenche J, Alsat E, Soncin F, Rochette-Egly C, Ebain-Brion D: Retinoid receptors expression in human term placenta: involvement of RXR alpha in retinoid induced-hCG secretion. J Clin Endocrinol Metab 1998, 83:1384-1387

36. Wang Q, Fujii H, Knipp GT: Expression of PPAR and RXR isoforms in the developing rat and human term placentas. Placenta 2002, 23:661-671

37. Dunn-Albanese LR, Ackerman WE 4th, Xie Y, Iams JD, Kniss DA: Reciprocal expression of peroxisome proliferator-activated receptorgamma and cyclooxygenase-2 in human term parturition. Am J Obstet Gynecol 2004, 190:809-816

38. Frew L, Sugiarto NU, Rajagopal SP, He J, Leask R, Norman JE, Riley SC, Stock SJ: The effect of omega-3 polyunsaturated fatty acids on the inflammatory response of the amnion. Prostaglandins Leukot Essent Fatty Acids 2013, 89:221-225

39. Ackerman WE 4th, Zhang XL, Rovin BH, Kniss DA: Modulation of cytokine-induced cyclooxygenase 2 expression by PPARG ligands through NFkappaB signal disruption in human WISH and amnion cells. Biol Reprod 2005, 73:527-535

40. Borel V, Gallot D, Marceau G, Sapin V, Blanchon L: Placental implications of peroxisome proliferator-activated receptors in gestation and parturition. PPAR Res 2008, 2008:758562

41. Pomini F, Caruso A, Challis JR: Interleukin-10 modifies the effects of interleukin-1beta and tumor necrosis factor-alpha on the activity and expression of prostaglandin $\mathrm{H}$ synthase-2 and the NAD+-dependent 15-hydroxyprostaglandin dehydrogenase in cultured term human villous trophoblast and chorion trophoblast cells. J Clin Endocrinol Metab 1999, 84:4645-4651

42. Challis JR, Lye SJ, Gibb W, Whittle W, Patel F, Alfaidy N: Understanding preterm labor. Ann N Y Acad Sci 2001, 943:225-234 